\title{
The Efficacy and Toxicity of Bupropion in the Elderly
}

\author{
William T. Howard M.D., M.S. \\ Johns Hopkins Department of Mental Hygiene \\ Julia K. Warnock M.D., Ph.D. \\ Department of Psychiatry, University of Oklahoma, Tulsa, OK
}

Follow this and additional works at: https://jdc.jefferson.edu/jeffjpsychiatry

Part of the Psychiatry Commons

Let us know how access to this document benefits you

\section{Recommended Citation}

Howard, William T. M.D., M.S. and Warnock, Julia K. M.D., Ph.D. (2000) "The Efficacy and Toxicity of Bupropion in the Elderly," Jefferson Journal of Psychiatry. Vol. 15 : Iss. 1 , Article 8.

DOI: https://doi.org/10.29046/JJP.015.1.004

Available at: https://jdc.jefferson.edu/jeffjpsychiatry/vol15/iss1/8

This Article is brought to you for free and open access by the Jefferson Digital Commons. The Jefferson Digital Commons is a service of Thomas Jefferson University's Center for Teaching and Learning (CTL). The Commons is a showcase for Jefferson books and journals, peer-reviewed scholarly publications, unique historical collections from the University archives, and teaching tools. The Jefferson Digital Commons allows researchers and interested readers anywhere in the world to learn about and keep up to date with Jefferson scholarship. This article has been accepted for inclusion in Jefferson Journal of Psychiatry by an authorized administrator of the Jefferson Digital Commons. For more information, please contact: JeffersonDigitalCommons@jefferson.edu. 


\title{
The Efficacy and Toxicity of Bupropion in the Elderly
}

\author{
William T. Howard, M.D., M.S. ${ }^{1}$ \\ and Julia K. Warnock, M.D., Ph.D. ${ }^{2}$
}

\begin{abstract}
Bupropion is an antidepressant with excellent tolerability and few side effects or drug interactions. These characteristics suite it well for use both in the elderly and in the medically ill. However, early reports of seizures with bupropion therapy in patients with bulimia limited its use. The pharmacology, efficacy, toxicity, and side effect profile of both the immediate release (IR) and the recently available sustained release $(S R)$ formulations of bupropion are reviewed. Bupropion $S R$ is associated with a reduced seizure incidence (0.1\%) compared to that found with the IR formulation (0.4\%). Recent reports, however, demonstrate that the half-life of bupropion is prolonged in the elderly and that the elderly accumulate bupropion metabolites. Potential toxic effects, including seizures and psychosis, may result from high bupropion plasma levels and the accumulation of bupropion metabolites in the elderly or in those with impaired renal or liver function. Clinical reports in the elderly demonstrate that lower ( $75-225 \mathrm{mg} /$ day) doses of bupropion are associated with fewer side effects and equal efficacy to that found with higher doses. Bupropion is a good antidepressant choice for the elderly and the medically ill, provided additional precautions, including the use of low doses, are taken. Bupropion should either be avoided or be used with extreme caution in anyone who is at increased risk of seizures or who has a history of psychosis or an eating disorder.
\end{abstract}

(Suggested Keywords, Index Medicus MeSH: Bupropion, Geriatric Psychiatry, Psychoses, Substance-Induced, Seizures, Depression, Pharmacokinetics, Antidepressive Agents, Psychogeriatrics, Psychopharmacology)

\section{INTRODUCTION}

Depression is a common psychiatric problem in the elderly, although the exact prevalence is uncertain. The National Institute of Mental Health (NIMH) Epidemiological Catchment Area (ECA) program found a prevalence rate of $2.5 \%$ for all affective disorders in people aged 65 years and older (1). However, depression can be difficult to recognize and may manifest differently in older adults. Thus, the ECA rate

\footnotetext{
'Johns Hopkins University, Departments of Psychiatry \& Mental Hygiene, Baltimore, Maryland

${ }^{2}$ University of Oklahoma, Department of Psychiatry, Tulsa, Oklahoma

This work was funded in part by the National Institute of Mental Health training grant 5T32MH14592
} 
may be an underestimate (2). Blazer (3) analyzed the ECA data and found that depressive symptoms were reported in $27 \%$ of those aged 60 years or older. This high prevalence of depressive symptoms in the elderly, together with this segment of the population increasing faster than any other, indicates the need for antidepressant therapy that is highly effective, well tolerated, and relatively free of side effects and drug interactions.

Bupropion (BUP), one of the "second generation" antidepressants, was originally introduced in 1985. The unicyclic aminoketone is a unique antidepressant in structure, (4) is well tolerated, and has few side effects (5) or drug interactions (6); these characteristics suite it particularly well for use both in the elderly and in the medically ill. In March 1986, however, bupropion immediate release (IR) was withdrawn from the market after reports indicated an increased rate of seizures in bulimic patients (7). In May 1989, bupropion IR was re-introduced with a reduced maximum dosage recommendation intended to decrease the incidence of seizures. In late 1996, the Food and Drug Administration (FDA) approved a sustained-release (SR) form of bupropion, which is reported to further reduce concerns about seizures. However, toxic effects in addition to seizures have been noted with bupropion, including the exacerbation or initiation of psychotic symptoms.

\section{PHARMACOLOGY}

Bupropion weakly blocks dopamine uptake (8). This is not believed to adequately account for its antidepressant activity, however, and a noradrenergic mechanism has also been suggested (8). Oral administration of bupropion results in rapid absorption, and bupropion undergoes extensive first pass metabolism (9). The metabolism of bupropion results in the formation of three major metabolites: hydroxybupropion (HB), threohydrobupropion (TB), and erythrohydrobupropion (EB) (9). Leizure (10) found the half lives of BUP, TB, EB, and HB to be 9.8, 19.8, 26.8, and 22.2 hours, respectively. In 1995, however, Sweet (11) found the half lives for BUP, TB, EB, and $\mathrm{HB}$ to be increased in the elderly at $32.4,38.8,61.4$, and 34.2 hours, respectively. Furthermore, the elderly accumulate an inordinate amount of bupropion metabolites (11). Metabolism of bupropion SR results in the same break down products as does metabolism of the IR form. Future study, however, will be necessary to learn more about the pharmacokinetic properties of bupropion SR and how these compare to the IR form. Excretion of bupropion occurs through the urine (87\%) and feces (10\%), with only $0.5 \%$ excreted unchanged (9). Decreases in liver function, and presumably kidney function, impair elimination, result in increased blood levels of bupropion and its metabolites, and increase the chance of toxicity (12).

\section{EFFICACY}

Kane, (13) in a study of 38 depressed patients 55 years or older, found no difference in efficacy between those randomly designated to receive either a mean bupropion dose of $323 \mathrm{mg} /$ day (high dose) or a mean of $150 \mathrm{mg} /$ day (low dose). 
Likewise, Branconnier, (14) in a study of 63 depressed patients 55 years or older, found no significant differences in efficacy between those randomly designated to receive bupropion at either $450 \mathrm{mg} /$ day (high dose) or $150 \mathrm{mg} /$ day (low dose). However, high dose bupropion demonstrated faster onset of action and greater anxiolytic activity than low dose bupropion. Preskorn (15) found a curvilinear relationship between antidepressant efficacy and bupropion trough plasma concentration, with efficacy decreased with either very high or very low trough plasma levels. Likewise, Golden (16) found poor efficacy to be associated with high bupropion metabolite concentrations. Bupropion is not the only antidepressant in which reduced doses in the elderly have been recommended. For example, Jarvic (17) found that doses as low as $25 \mathrm{mg}$ and $50 \mathrm{mg} /$ day of imipramine are effective in treating older adults with depression. Jarvic (17) also noted that further dosage increases were not likely to be successful but were likely to produce undesirable side effects.

\section{SIDE EFFECTS}

Overall, bupropion is well tolerated and exhibits few side effects (5). For example, Feighner (5) found no difference in treatment-emergent adverse events between bupropion and fluoxetine, one of the selective serotonin reuptake inhibitors (SSRIs). Agitation and excitement are the most common side effects associated with the discontinuation of bupropion (18). Although Prien (19) has suggested that bupropion may be associated with antidepressant induced mania less often than with other antidepressants, rare reports of bupropion induced mania do exist. For example, Bittman (20) reports the case of a 78 year old man taking lithium who became grandiose and manic when bupropion was started. Bupropion demonstrates little to no anticholinergic, antihistiminic, or antiadrenergic effect (21). There is no known cardiotoxicity and it does not cause orthostatic hypotension (22). In fact, bupropion has been found to be a useful agent in treating patients with heart disease $(23,24)$. On average, bupropion causes only mild weight loss and minimally affects appetite (25). Bupropion is the only antidepressant reported to improve sexual function (26). Few drug interactions have been noted with bupropion, and inhibition of cytochrome $\mathrm{P} 450$ liver isoenzymes has not been reported (6). Thus, not only is bupropion free of many of the side effects of the older tricyclic antidepressants, but also it has the following advantages over the newer selective serotonin re-uptake inhibitors: fewer sexual side effects, fewer drug interactions, and an absence of liver enzyme inhibition.

\section{BUPROPION AND SEIZURES}

In 1989, Davidson, (27) in a review of over four thousand cases, concluded that the incidence of seizures associated with bupropion therapy is approximately $0.4 \%$; this was deemed to be either no different from or just slightly higher than the incidence of seizures with the use of other tricyclic and tetracyclic antidepressants. In 1993 , a prospective study with over three thousand patients reproduced this same $0.4 \%$ seizure incidence rate with bupropion therapy (28). Davidson (27) found that 
several patient characteristics were associated with an increased risk of seizure with bupropion usage: prior history of seizures, history of organic brain disease, history of an eating disorder, doses greater than $450 \mathrm{mg} / \mathrm{day}$, rapid dose escalation, and high plasma levels of bupropion or its metabolites. To minimize the risk of seizures, the 1998 Physicians Desk Reference (29) (PDR) recommends an initial bupropion IR dose of $100 \mathrm{mg}$ twice a day for a minimum of three days before increasing the dose to $100 \mathrm{mg}$ three times a day. If in a few weeks response is not adequate the dose can be raised to a maximum of $450 \mathrm{mg} /$ day (29).

Peak bupropion plasma levels are $50 \%$ lower with the SR formulation than with the IR form (6). The risk of seizures with bupropion therapy is correlated with the peak plasma level. Therefore it is not surprising that the incidence of seizures with the SR formulation, with doses not exceeding $300 \mathrm{mg} /$ day, is lower $(0.1 \%)$ than that found with the IR form ( $0.4 \%)$ (30). The efficacy and side effect profile of the two forms of bupropion are otherwise similar (6). The PDR recommends beginning bupropion SR treatment at $150 \mathrm{mg} /$ day as a single dose (29). This can be increased to $150 \mathrm{mg}$ twice a day, the recommended target dose, as early as day four (29). A maximum dose of $200 \mathrm{mg}$ twice a day is recommended (29). However, given high plasma bupropion levels and accumulation of bupropion metabolites in the elderly, even the target dose of $300 \mathrm{mg} /$ day of bupropion SR may be excessive when treating geriatric depression.

\section{BUPROPION AND PSYCHOSIS}

A review of the literature uncovered seven cases of bupropion treatment emergent psychosis or delirium with psychotic features (31-37). Golden (31) reported that four out of 13 bupropion treated patients developed psychotic symptoms, only one of who had no history of psychosis. In two of the cases, psychotic symptoms appeared to be dose-related. Likewise, Goode (32) reported that three out of nine patients diagnosed with schizoaffective disorder experienced exacerbations of psychotic symptoms when treated with bupropion. Becker (33) reported that two out of twelve patients, both of who had a previous diagnosis of schizophrenia, experienced aberrant beliefs and visual experiences with bupropion treatment. Van-Putten (34) reported a case of acute delirium with psychotic features in a patient treated with bupropion. Ames (35) reported three cases of bupropion induced psychosis, with emergent symptoms including delusions as well as auditory and visual hallucinations. A history of psychotic symptoms was present in two of the three individuals. Bupropion my precipitate psychosis by blocking dopamine uptake and causing dopaminergic overdrive (36). Liberzon (36) reported a case of bupropion treatment emergent delirium with psychotic features in a patient who had a history of psychosis and was taking the dopamine agonist amantadine. Goetz (37) reported the onset or worsening of hallucinations or confusion with bupropion treatment in three patients with Parkinsons disease who were receiving a dopamine agonist, either amantadine or levodopa. From this review, bupropion induced psychosis appears to be more likely to occur in patients with certain risk factors. Vulnerable patients include those taking 
dopaminergic medications or those with a history of psychosis (31-37). Johnston (38) recommends that, in patients with a history of psychosis, bupropion not be used as first line treatment.

These reports contrast with the less than $4 \%$ rate of treatment emergent psychotic symptoms reported in a total of 2,398 patients who received bupropion up to 1985 (38). Thus, the incidence of treatment emergent psychosis with bupropion, when individual patient characteristics are disregarded, appears to be no greater than that seen with other antidepressants (38). However, the preceding data suggest that bupropion is capable of inducing or exacerbating psychotic symptoms, particularly in the presence of certain vulnerabilities.

\section{DISCUSSION}

The elderly may be more vulnerable to bupropion induced psychosis and other toxic effects than younger adults with depression. A possible mechanism for increased risk of bupropion toxicity in the elderly is that they have high peak plasma bupropion levels and accumulate bupropion metabolites (11). The elderly are also more likely than younger adults to have impairments of liver or kidney function, both of which are expected to result in elevated bupropion and bupropion metabolite levels (12). Untoward drug interactions are another possible explanation for bupropion induced toxic effects, although drug interactions have been reported rarely with bupropion (39). Onset or worsening of psychosis and confusion has been associated with concomitant administration of bupropion with the dopamine agonists levodopa (37) and amantadine (36), findings which support the dopaminergic overdrive hypothesis. Lithium (35) and selective serotonin reuptake inhibitors (34) have likewise been associated with the onset or worsening of delirium or psychosis when combined with bupropion.

In conclusion, bupropion possesses many characteristics that offer advantages over other antidepressants in the treatment of depression both in the elderly and in the medically ill; these include excellent tolerability, few side effects (5), and an absence of P450 liver enzyme inhibition or drug interactions (6). However, potential toxic effects, particularly seizures and psychosis, may result from high bupropion plasma levels and from the accumulation of bupropion metabolites in the elderly or in those with impaired renal or liver function (12). Patients receiving dopaminergic medications are also at increased risk of developing psychotic symptoms when given bupropion $(36,37)$. Thus, low doses $(75-225 \mathrm{mg} /$ day) of bupropion are recommended in the elderly, those with liver or renal dysfunction, and in those already taking dopamine agonists. In addition, bupropion should either be avoided or used with extreme caution in anyone who is at increased risk of seizures or who has a history of psychosis or an eating disorder. Also, bupropion should not be combined with other medications known to lower the seizure threshold. Future work establishing a therapeutic plasma level range for bupropion in the elderly would facilitate the safe and effective use of this unique antidepressant. 


\section{REFERENCES}

1. Regier DA, Boyd JH, Burke JD, et al: One-month prevalence of mental disorders in the United States: Based on five Epidemiologic Catchment Area sites. Arch Gen Psychiatry 1988; 45: 977-986.

2. Zisook S, Downs NS: Diagnosis and treatment of depression in late life. J Clin Psychiatry 1998; 59(Suppl 4): 80-91.

3. Blazer D, Hughes DC, George LK: The epidemiology of depression in an elderly community population. Gerontologist 1987; 27: 281-287.

4. Mehta NB: The chemistry of bupropion. J Clin Psychiatry 1983; 44: 56-59.

5. Feighner JP, Gardner EA, Johnston JA, et al: Double-blind comparison of bupropion and fluoxetine in depressed outpatients. J Clin Psychiatry 1991; 52: 329-335.

6. Davidson JR, Connor KM: Bupropion sustained release: a therapeutic overview. J Clin Psychiatry 1998; 59(Suppl 4): 25-31.

7. Horne RL, Ferguson JM, Pope HG, et al: Treatment of bulimia with bupropion: a multicenter controlled trial. J Clin Psychiatry 1988; 49: 262-266.

8. Ascher JA, Cole JO, Colin JN, et al: Bupropion: a review of its mechanism of antidepressant activity. J Clin Psychiatry 1995; 56: 395-401.

9. Schroeder DH: Metabolism and kinetics of bupropion.J Clin Psychiatry 1983; 44: 79-81.

10. Laizure SC, DeVane CL, Stewart JT, et al: Pharmacokinetics of bupropion and its major basic metabolites in normal subjects after a single dose. Clin Pharmacol Ther 1985; 38: $586-589$.

11. Sweet RA, Pollock BG, Kirshner M, et al: Pharmacokinetics of single- and multiple-dose bupropion in elderly patients with depression. J Clin Pharmacol 1995; 35: 876-884.

12. DeVane CL, Laizure SC, Stewart JT, et al: Disposition of bupropion in healthy volunteers and subjects with alcoholic liver disease. J Clin Psychopharmacol 1990; 10: 328-332.

13. Kane JM, Cole K, Sarantakos S, et al: Safety and efficacy of bupropion in elderly patients: preliminary observations. J Clin Psychiatry 1983; 44: 134-136.

14. Branconnier RJ, Cole JO, Ghazvinian S, et al: Clinical pharmacology of bupropion and imipramine in elderly depressives. J Clin Psychiatry 1983; 44: 130-133.

15. Preskorn SH: Antidepressant response and plasma concentrations of bupropion. J Clin Psychiatry 1983; 44: 137-139.

16. Golden RN, DeVane CL, Laizure SC, et al: Bupropion in depression, II: the role of metabolites in clinical outcome. Arch Gen Psychiatry 1988; 45: 145-149.

17. Jarvik LF, Mintz J, Steuer J, et al: Treating geriatric depression: a 26-week interim analysis. J Am Geriatr Soc 1982; 30: 713-717.

18. Wright G, Galloway L, Kim J, et al: Bupropion in the long-term treatment of cyclic mood disorders: mood stabilizing effects. J Clin Psychiatry 1985; 46: 22-25.

19. Prien RF, Gelenberg AJ: Alternatives to lithium for preventive treatment of bipolar disorder. Am J Psychiatry 1989; 146: 840-848.

20. Bittman BJ, Young RC: Mania in an elderly man treated with bupropion. Am J Psychiatry 1991; 148: 541.

21. Van Wyck Fleet J, Manberg PJ, Miller LL, et al: Overview of clinically significant adverse reactions to bupropion. J Clin Psychiatry 1983; 44: 191-196.

22. Wenger TL, Stern WC: The cardiovascular profile of bupropion. J Clin Psychiatry 1983; 44: 176-182. 
23. Roose SP, Dalack GW, Glassman AH, et al: Cardiovascular effects of bupropion in depressed patients with heart disease. Am J Psychiatry 1991; 148: 512-516.

24. Roose SP, Glassman AH, Giardina EGV, et al: Cardiovascular effects of imipramine and bupropion in depressed patients with congestive heart failure. J Clin Psychopharmacol 1987; 7: 247-251.

25. Harto-Truax N, Stern WC, Miller LL, et al: Effects of bupropion on body weight. J Clin Psychiatry 1983; 44: 183-186.

26. Crenshaw TL, Goldberg JP, Stern WC: Pharmacologic modification of psychosexual dysfunction. J Sex Marital Ther 1987; 13: 239-252.

27. Davidson J: Seizures and bupropion: a review. J Clin Psychiatry 1989; 50: 256-261.

28. Johnston JA, Lineberry CG, Ascher JA, et al: A 102-center prospective study of seizure in association with bupropion. J Clin Psychiatry 1991; 52: 450-456.

29. Physicians' Desk Reference, 52nd Edition. Montvale NJ, Medical Economics Company, Inc, 1998.

30. Settle EG: Bupropion sustained release: side effect profile. J Clin Psychiatry 1998; 59(Suppl 4): 32-36.

31. Golden RN, James SP, Sherer MA, et al: Psychoses associated with bupropion treatment. Am J Psychiatry 1985; 142: 1459-1462.

32. Goode DJ, Manning AA: Comparison of bupropion alone and with haloperidol in schizoaffective disorder, depressed type. J Clin Psychiatry 1983; 44: 253-255.

33. Becker RE, Dufresne RL: Perceptual changes with bupropion, a novel antidepressant. Am J Psychiatry 1982; 139: 1200-1201.

34. Van-Putten T, Shaffer I: Delirium associated with bupropion. J Clin Psychopharmacol 1990; 10: 234.

35. Ames D, Wirshing WC, Szuba MP: Organic mental disorders associated with bupropion in three patients. J Clin Psychiatry 1992; 53: 53-55.

36. Liberzon I, Dequardo JR, Silk KR: Bupropion and delirium. Am J Psychiatry 1990; 147: 12.

37. Goetz CG, Tanner CM, Klawans HL, et al: Bupropion in parkinson's disease. Neurology 1984; 34: 1092-1094.

38. Johnston JA, Lineberry CG, Frieden CS: Prevalence of psychosis, delusions, and hallucinations in clinical trials with bupropion. Am J Psychiatry 1986; 143: 1192-1193.

39. Goodnick PJ: Pharmacokinetics of second generation antidepressants: Psychopharmacol Bull 1991; 27: 513-519. 